\title{
Model Waterfall Untuk Rancang Bangun Sistem Informasi Pengadaan Mesin EDC Pada E-Channel Operations Perbankan
}

\author{
Muhammad Reza Aldiansyah ${ }^{1}$, Amrin² $^{2}$ \\ ${ }^{1,2}$ Universitas Bina Sarana Informatika \\ e-mail: ${ }^{1}$ relanzah@gmail.com, ${ }^{2}$ amrin.ain@bsi.ac.id
}

\begin{abstract}
Abstrak - Dalam era globalisasi sekarang ini, teknologi informasi melaju dengan cepatnya. Adapun komputer yang merupakan peralatan yang diciptakan untuk mempermudah pekerjaan manusia, saat mencapai kemajuan baik di dalam pembuatan hardware maupun software. E-Channel Operations Perbankan membutuhkan sekali adanya suatu sistem informasi yang menunjang dan memberikan pelayanan yang memudahkan bagi para karyawannya. Sistem pengadaan yang digunakan E-Channel Operations Perbankan masih dilakukan secara manual, yaitu dengan membuat surat permintaan setiap kali melakukan pengadaan mesin baru. Perancangan sistem informasi pengadaan mesin EDC berbasis web merupakan solusi yang terbaik untuk memecahkan permasalahan- permasalahan yang ada pada perusahaan ini, serta dengan sistem yang terkomputerisasi dapat tercapai suatu kegiatan yang efektif dan efisien dalam menunjang aktifitas pada perusahaan ini. Metode yang digunakan untuk pengembangan perangkat lunak adalah metode waterfall. Hasil dari penelitian ini adalah dengan adanya aplikasi pengadaan mesin EDC, dapat mempermudah pegawai yang terkait dalam proses pengadaan secara real time, pembuatan laporan dapat dilakukan secara cepat dan tepat.serta penyimpanan data menjadi lebih aman.
\end{abstract}

Kata Kunci: sistem informasi, mesin EDC, metode waterfall

Abstract - Right now in this era of globalization, the information technology accelerates so fast. Meanwhile with the presence of computer which is one of many sophisticated instruments made by people is really helpful and to ease people's work due to the emerging of both the hardware and software. E-Channel Operations Perbankan requires an information system that supports and provides services that make it easier for its employees. The procurement system used by E-Channel Operations Perbankan is still done manually, that is by making a request letter every time a new machine is procured. The design of a web-based EDC machine procurement information system is the best solution to solve the problems that exist in this company, and with a computerized system an effective and efficient activity can be achieved in supporting activities in this company. The method used for software development is the waterfall method. The result of this research is that with the EDC machine procurement application, it can make it easier for employees involved in the procurement process in real time, report generation can be done quickly and precisely. And data storage becomes more secure.

Keywords: information system, EDC machine, waterfall method

\section{PENDAHULUAN}

Pengadaan merupakan sebuah proses kegiatan untuk pemenuhan atau penyediaan kebutuhan dan pasokan barang atau jasa di bawah kontrak atau pembelian secara langsung untuk memenuhi kebutuhan dalam bisnis. Pengadaan barang atau jasa bisa terjadi di BUMN dan perusahaan swasta nasional maupun internasional. Intinya, pengadaan barang atau jasa dibuat untuk memenuhi kebutuhan perusahaan atau instansi pemerintah akan barang atau jasa yang dapat menunjang kinerja dan performa mereka.

E-Channel Operations memegang tanggung jawab atas pengelolaan, peremajaan dan pengadaan mesin EDC agar tercapai tingkat layanan yang memuaskan. Menurut (Hayati \& Lestariningati, 2018) "Pengertian dari Electronic Data Capture (EDC) yaitu merupakan sebuah sistem yang memiliki layanan seperti mini ATM. EDC berfungsi sebagai media transaksi dan pembayaran elektronik". Dalam melakukan pengadaan mesin EDC, E-Channel operations masih menggunakan metode manual, sehingga prosedurnya memakan waktu lama dalam proses pengadaan. Adapun masalah yang dihadapi adalah harus membuat surat setiap kali mengajukan pengadaan mesin EDC.

Karena sistem yang dipakai masih memakai sistem manual sehingga banyak prosedur yang perlu diurus sehingga penulis memberikan solusi agar sistem diubah menjadi sistem terkomputerisasi dengan dibuatnya aplikasi pengadaan mesin EDC.

Sebagai bahan acuan dan perbandingan, peneliti melakukan studi literature pada beberapa penelitian sebelumnya terkait dengan metode dan sistem yang digunakan. Diantaranya penelitian yang dilakukan oleh (Firdaus \& Masya, 2020) tentang Aplikasi Informasi Pengaduan Electronic Data 
Capture Merchant ( Edc ) Berbasis Web. Penelitian yang dilakuukan oleh (Asna, 2020) tentang Pengembangan sistem inventarisasi mesin electronic data capture (edc) berbasis web di pt. bank mandiri (persero) tbk region vii/jawa 2. Selanjutnya penelitian yang dilakukan oleh (Farid, 2018) tentang Perancangan Sistem Informasi Dengan Mengintegrasikan Sistem Trouble Shooting Solution Mesin Electronic Data Capture (EDC) Berbasis Web Pada PT Bank Rakyat Indonesia (Persero), Tbk Kantor Cabang Pondok Gede. Penelitian yang dilakukan oleh (Hayati \& Lestariningati, 2018) tentang Electronic Data Capture (Edc) Berbasis Mini Pc Raspberry Pi. Kemudian penelitian yang dilakukan oleh (Mudiar \& Hidayat, 2019) tentang Sistem Informasi Manajemen Asset Berbasis Web Pada Perbanas Institute. Kemudian penelitian yang dilakukan (Astuti \& Subhiyakto, 2017) yang berjudul Pengembangan Sistem Informasi Dengan Metode Waterfall Untuk Pengarsipan Data Wajib Pajak. Selanjutnya penelitian yang dilakukan oleh (Dewi, dkk) Tentang Analisis Dan Perancangan Sistem Informasi Manajemen Aset Tetap Pada PT. Metis Teknologi. Penelitian yang dilakukan oleh (Priyono \& Amrin, 2019) tentang Sistem Informasi Pengelolaan Sertifikat Tanah Pada Badan Pertanahan Nasional Jakarta. Terakhir Penelitian yang dilakukan oleh (Mariana \& Amrin, 2019) yang berjudul Implementasi Model Waterfall Untuk Pengembangan Sistem Informasi Surat Berjalan PKK DKI Jakarta.

\section{METODE PENELITIAN}

Metode penelitian adalah suatu cara atau prosedur yang dipergunakan untuk melakukan penelitian sehingga mampu menjawab rumusan masalah dan tujuan penelitian. Dalam metode penelitian ini, penulis menggunakan metode pengumpulan data dan metode pengembangan perangkat lunak. Adapun penjelasannya sebagai berikut:

\section{A. Metode Pengumpulan Data}

Adapun metode pengumpulan data yang penulis gunakan dalam penyusunan penelitian ini adalah sebagai berikut:

\section{Pengamatan Langsung (Observation)}

Disini penulis melakukan metode pengamatan langsung terhadap kegiatan yang berhubungan dengan masalah yang diambil. Hasil dari pengamatan tersebut langsung dicatat. Dari kegiatan observasi ini dapat diketahui urutan proses dari kegiatan tersebut.

2. Wawancara (Interview)

Dalam pembuatan laporan Tugas Akhir ini, penulis melakukan metode tanya jawab atau wawancara kepada pegawai mengenai semua kegiatan yang berhubungan dengan Pengadaan Mesin EDC Pada E-Channel Operations untuk mendapatkan informasi secara lengkap.

3. Studi Pustaka

Selain melakukan kegiatan tersebut diatas penulis juga melakukan studi kepustakaan melalui literatur-literatur atau referensireferensi yang ada diperpustakaan Akademi Manajemen Informatika Bina Sarana

Informatika maupun di perpustakaan lainnya.

\section{B. Metode Pengembangan Perangkat Lunak}

Pada penelitian ini, model pengembangan sistem informasi yang digunakan adalah waterfall. Waterfall adalah model pengembangan perangkat lunak yang paling banyak digunakan. Menurut (Sukamto \& Salahuddin, 2014) mengemukakan bahwa Model SDLC air terjun (waterfall) sering juga disebut model sekuensial linier (Sequential linier) atau alur hidup klasik (classic life cycle)." Model air terjun menyediakan pendekatan alur hidup perangkat lunak secara sekuensial atau terurut dimulai dari analisis, desain, pengodean, pengujian dan tahap pendukung (support). Berikut adalah gambar air terjun:

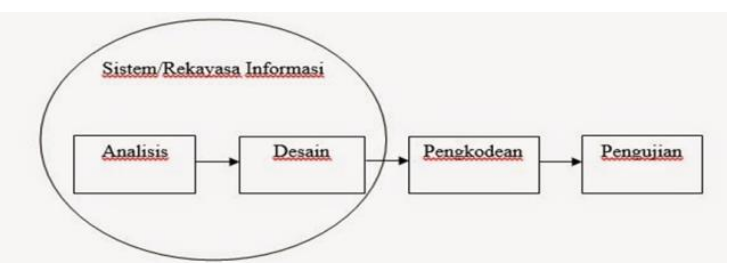

Gambar 1. Model Pengembangan Waterfall

Aktivitas-aktivitas dalam waterfall model adalah sebagi berikut :

1. Analisis kebutuhan perangkat lunak

Proses pengumpulan kebutuhan dilakukan secara intensif untuk menspesifikasikan kebutuhan perangkat lunak agar dapat dipahami perangkat lunak seperti apa yang dibutuhkan oleh user. Spesifikasi kebutuhan perangkat lunak pada tahap ini perlu di dokumentasikan.

2. Desain

Desain perangkat lunak adalah proses multi langkah yang fokus pada desain pembuatan program perangkat lunak termasuk struktur data, arsitektur perangkat lunak, representasi antarmuka, dan prosedur pengodean. Tahap ini mentranslasi kebutuhan perangkat lunak dari tahap analisis kebutuhan ke representasi desain agar dapat diimplementasikan menjadi program pada tahap selanjutnya. Desain perangkat lunak yang dihasilkan pada tahap ini juga perlu didokumentasikan.

3. Pembuatan Kode Program

Desain harus ditranslasikan ke dalam program perangkat lunak. Hasil dari tahap ini adalah program komputer sesuai dengan desain yang telah dibuat pada tahap desain.

4. Pengujian

Pengujian fokus pada perangkat lunak secara dari segi lojik dan fungsional dan memastikan bahwa semua bagian sudah diuji. Hal ini dilakukan 
untuk meminimalisir kesalahan (error) dan memastikan keluaran yang dihasilkan sesuai yang diinginkan.

\section{HASIL DAN PEMBAHASAN}

\section{A. Analisis Kebutuhan}

1. Kebutuhan Pengguna

Dalam sistem pengadaan mesin EDC ini, terdapat tiga pengguna yang dapat saling berinteraksi dalam lingkungan sistem, yaitu: Karyawan, Gudang, dan Admin. Ketiga pengguna tersebut memiliki karakteristik interaksi dengan sistem yang berbedabeda dan memiliki kebutuhan informasi yang berbeda-beda, seperti berikut :

A1 Skenario Kebutuhan Karyawan

a) Mengelola data mesin

b) Membuat pengadaan mesin

c) Melihat status pesanan

d) Mencetak laporan

e) Mengganti password

A2 Skenario Kebutuhan Admin
a) Menerima pengadaan mesin dari karyawan
b) Mengelola pengadaan mesin
c) Mengelola pesanan
d) Mengelola data user
e) Mencetak laporan
f) Mengganti password

A3 Skenario Kebutuhan Gudang
a) Menerima pesanan mesin dari Admin
b) Mengelola pesanan mesin
c) Mencetak laporan
d) Mengganti password

2. Kebutuhan Sistem

1) Pengguna harus melakukan login untuk mengakses aplikasi dengan memasukkan username dan password agar privasi pengguna aman.

2) Pengguna harus melakukan logout setelah selesai menggunakan aplikasi.

3) Sistem akan melakukan kalkulasi stok barang.

4) Sistem akan menampilkan menu sesuai dengan hak akses yang dibuka.

\section{B. Perancangan Sistem (Desain)}

1. Rancangan Diagram Use Case

Use case diagram menjelaskan hubungan atau interaksi antara use case dan actor. Use case diagram sistem informasi yang akan dibangun dapat dilihat pada Gambar 2.

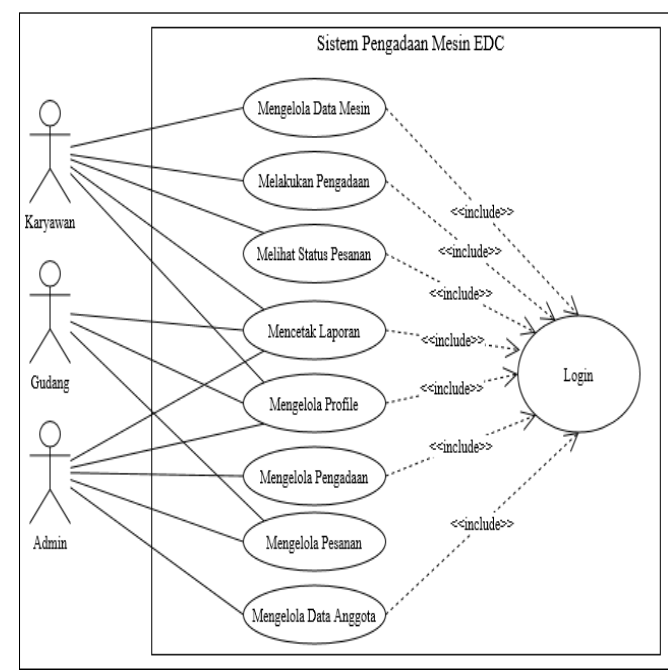

Gambar 2. Use Case Diagram Pengadaan Mesin EDC

2. Class Diagram

Class Diagram menggambarkan struktur statis class di dalam sistem. Gambar 3 menunjukkan Class Diagram dari sistem yang akan dibangun.

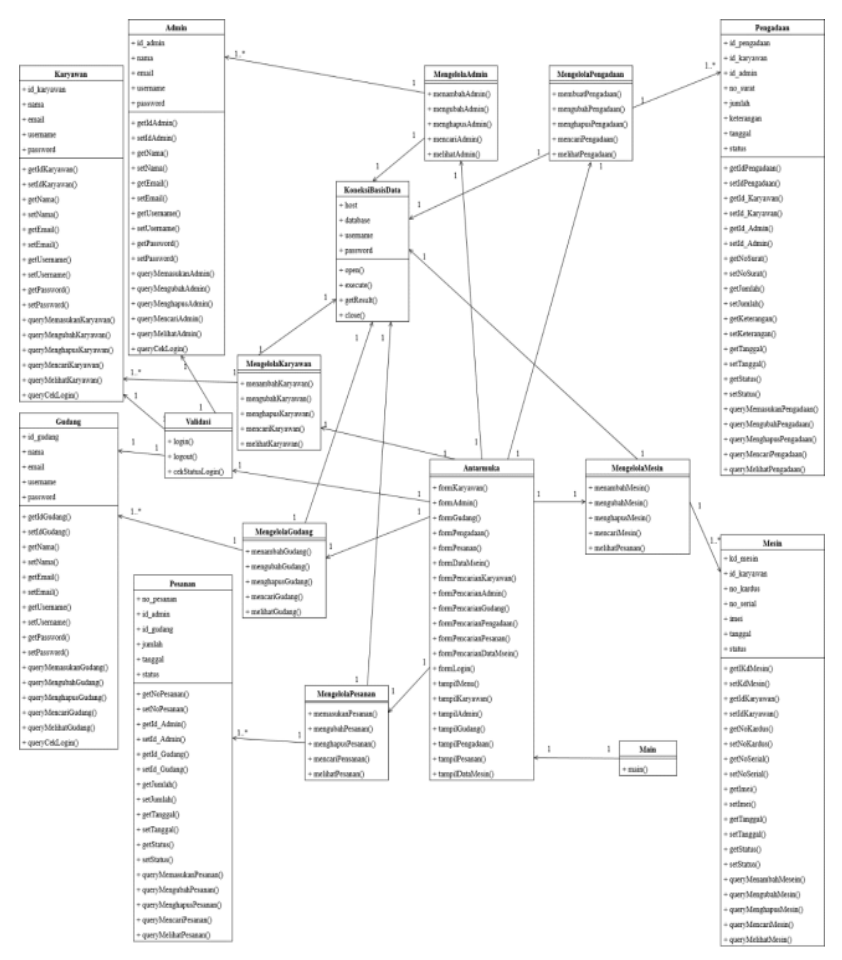

Gambar 3. Rancangan Class Diagram 
3. ERD (Entity Relatioship Diagram)

Perancangan basis data menghasilkan pemetaan tabel-tabel yang digambarkan dengan Entity Relationship Diagram (ERD). Berikut ERD untuk perancangan sistem yang dibangun:

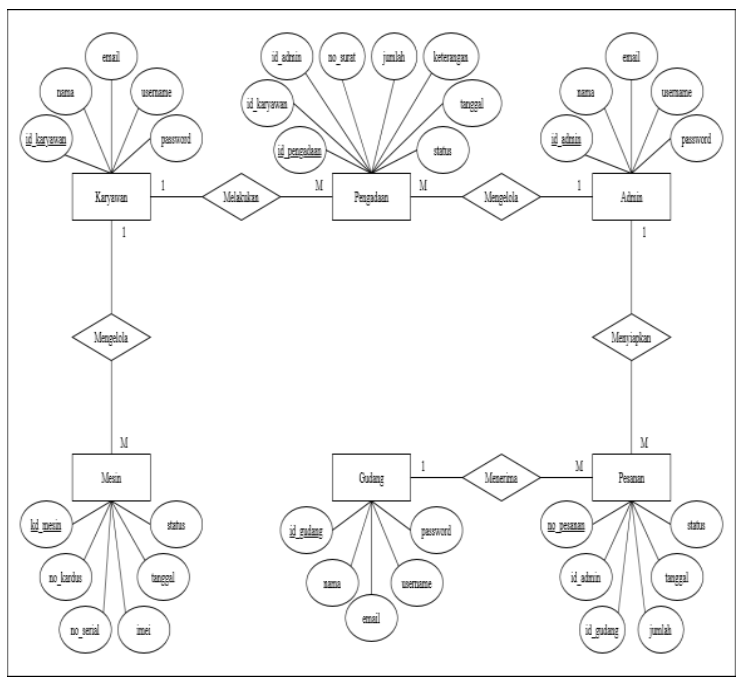

Gambar 4. Entity Relationship Diagram (ERD)

\section{Implementasi Rancangan Antar Muka}

Rancangan ini merupakan bagian yang berisi mengenai penggambaran interface dari bahasa pemprograman yang dibuat sesuai dengan sistem usulan yang dibuat.

1. Interface Login Website

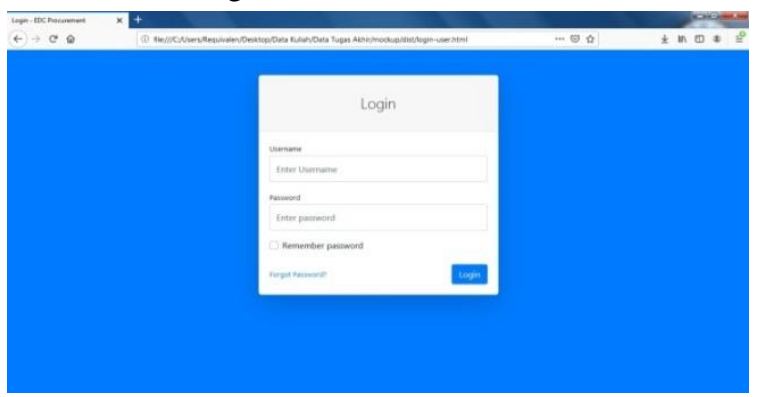

Gambar 5. Rancangan Interface Login

2. Interface Menu Data Mesin EDC Hak Akses Karyawan

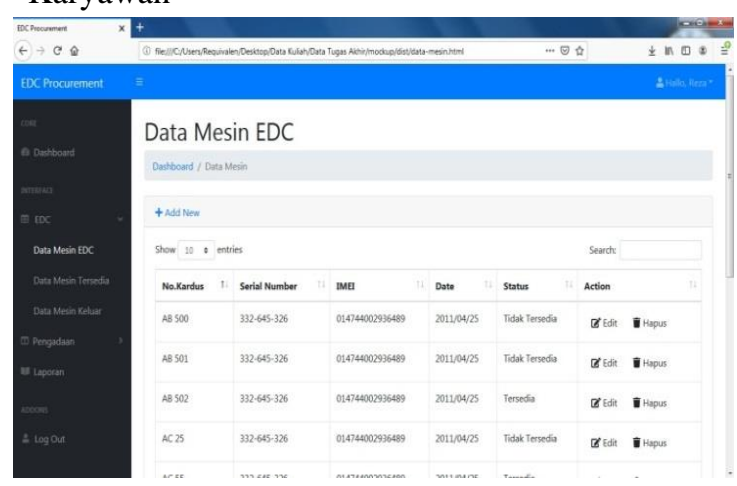

Gambar 6. Rancangan Interface Menu Data Mesin
3. Interface Form Tambah Data Mesin EDC Hak Akses Karyawan

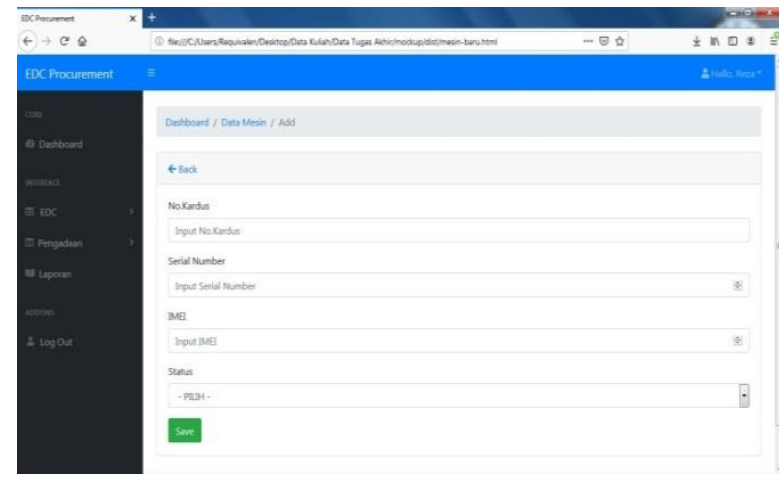

Gambar 7. Rancangan Interface Form Tambah Data Mesin EDC

4. Interface Form Pengadaan Mesin Hak Akses Karyawan

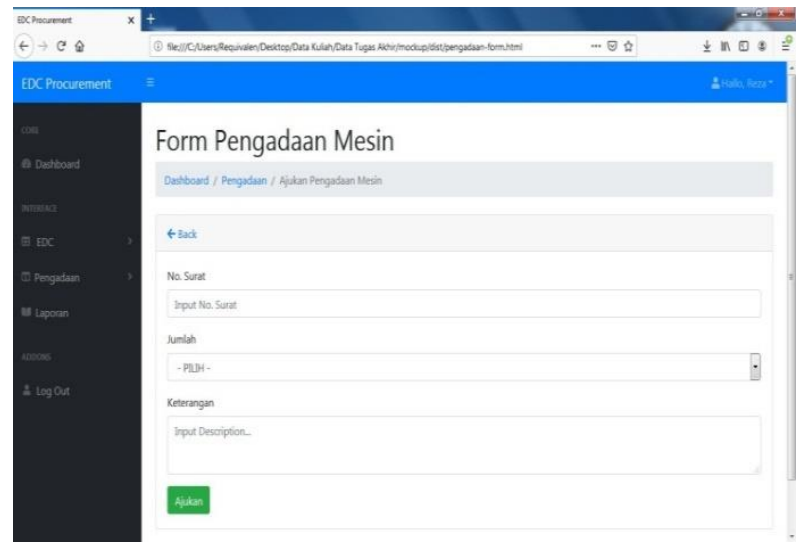

Gambar 8. Rancangan Interface Form Pengadaan Mesin

5. Interface Menu Utama Hak Akses Admin

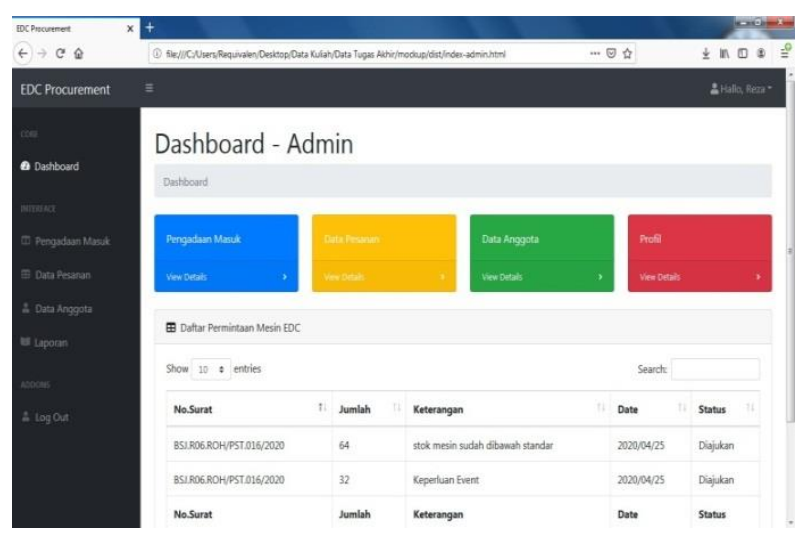

Gambar 9. Rancangan Interface Menu Utama Admin 
6. Interface Menu Data Pesanan Hak Akses Admin

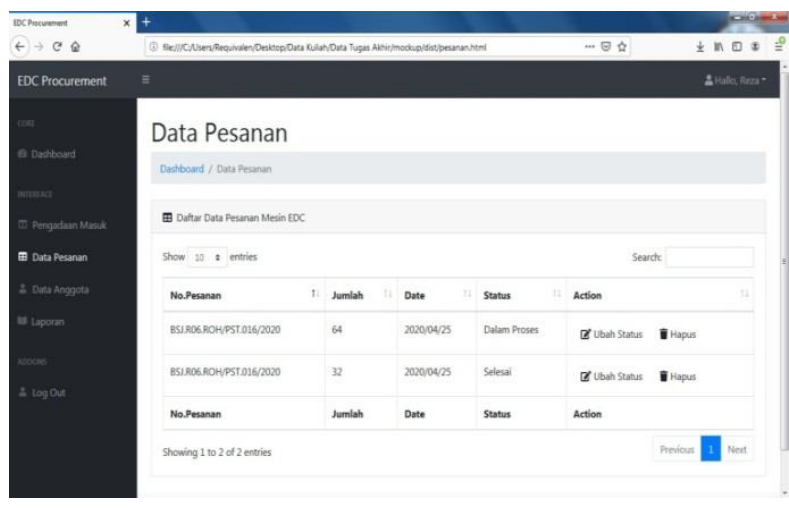

Gambar 10. Rancangan Interface Menu

Data Pesanan Admin

7. Interface Menu Data Anggota Hak Akses Admin

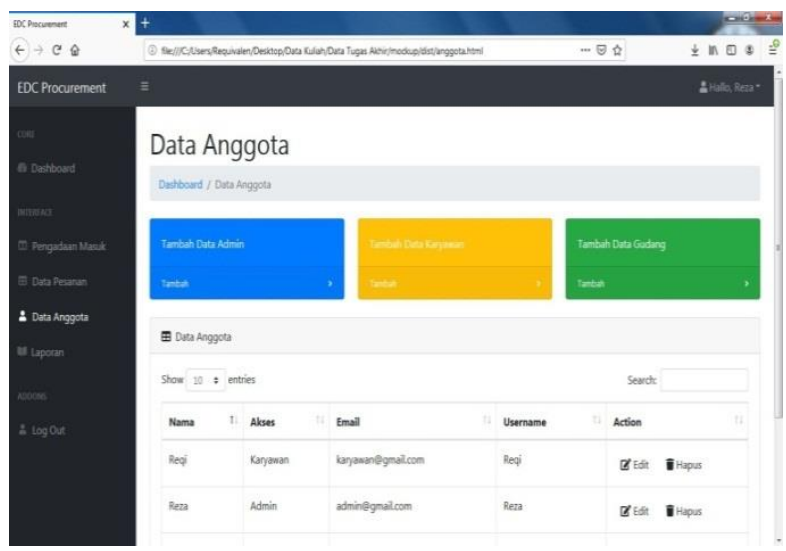

Gambar 11. Rancangan Interface Menu Data Anggota

8. Interface Menu Utama Hak Akses Gudang

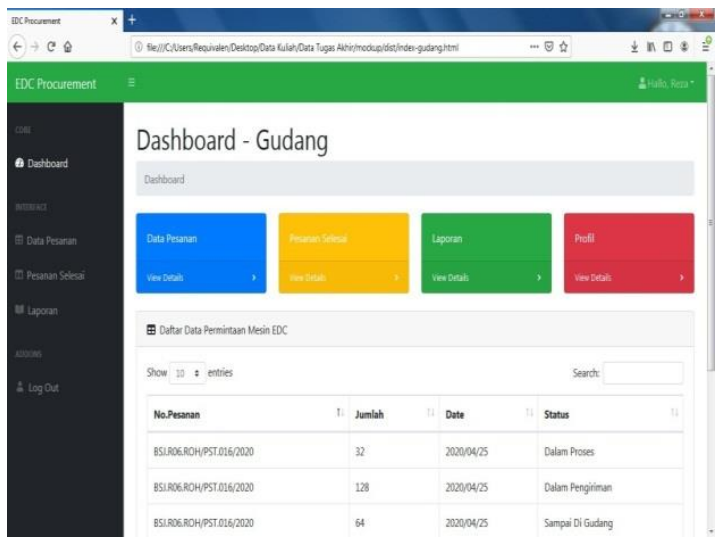

Gambar 12. Rancangan Interface Menu Utama Gudang
9. Interface Menu Data Pesanan Hak Akses Gudang

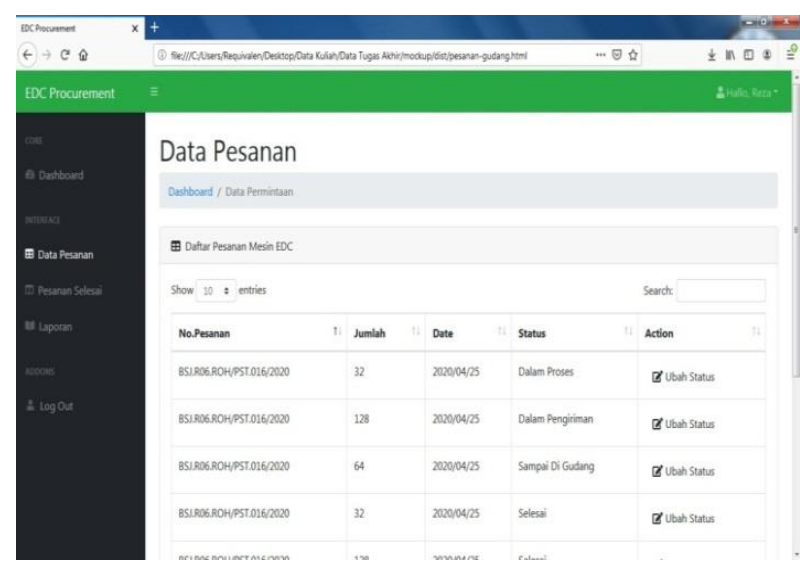

Gambar 13. Rancangan Interface Menu Data Pesanan Gudang

\section{KESIMPULAN}

Berdasarkan hasil dan pembahasan mengenai Perancangan Sistem Pengadaan Mesin EDC, maka dapat diambil kesimpulan sebagai berikut:

1. Dengan adanya aplikasi pengadaan mesin edc, dapat mempermudah pegawai yang terkait dan mengefisiensikan waktu pada saat proses pengadaan terjadi.

2. Dengan adanya aplikasi pengadaan mesin edc, pegawai yang terkait dapat mengetahui proses pengadaan secara real time tanpa harus menelpon kantor pusat dan gudang.

3. Dengan adanya aplikasi pengadaan mesin edc, pembuatan laporan dapat dilakukan dengan cepat dan tepat.

4. Dengan adanya aplikasi pengadaan mesin edc, penyimpanan data menjadi lebih aman karena tersimpan ke dalam database.

\section{REFERENSI}

Asna, M. (2020). Pengembangan sistem inventarisasi mesin electronic data capture (edc) berbasis web di pt. bank mandiri (persero) tbk region vii/jawa 2. Universitas Negeri Padang.

Astuti, Y. P., \& Subhiyakto, E. R. (2017). Pengembangan Sistem Informasi Dengan Metode Waterfall Untuk Pengarsipan Data Wajib Pajak. Jurnal Teknologi Informasi UDINUS, 16(2), 106-113.

Farid, A. F. (2018). Perancangan Sistem Informasi Dengan Mengintegrasikan Sistem Trouble Shooting Solution Mesin Electronic Data Capture (EDC) Berbasis Web Pada PT Bank 
Rakyat Indonesia (Persero), Tbk Kantor Cabang Pondok Gede. Universitas Bhayangkara Jakarta.

Firdaus, F., \& Masya, F. (2020). Aplikasi Informasi Pengaduan Electronic Data Capture Merchant ( Edc ) Berbasis Web. Jurnal Explore, 11(1), $17-22$.

Hayati, A. P., \& Lestariningati, S. I. (2018). Electronic Data Capture ( Edc ) Berbasis Mini Pc Raspberry Pi. Jurnal Teknik Komputer Unikom-Komputika, 7(1).

Mariana, A. N., \& Amrin, A. (2019). Implementasi Model Waterfall Untuk Pengembangan Sistem Informasi Surat Berjalan PKK DKI Jakarta. Jurnal Riset Komputer (Jurikom), 6(5), 453$459 . \quad$ https://www.ejurnal.stmik- budidarma.ac.id/index.php/jurikom/article/vie w/1392

Mudiar, W., \& Hidayat, U. (2019). Sistem Informasi Manajemen Asset Berbasis Web Pada Perbanas Institute. Information Management for Educators and Professionals, 4(1), E ISSN: 2548-3331.

Priyono, A. H., \& Amrin, A. (2019). Sistem Informasi Pengelolaan Sertifikat Tanah Pada Badan Pertanahan Nasional Jakarta. Jurnal Mantik Penusa, 3(2), 30-37. http://ejurnal.pelitanusantara.ac.id/index.php/mantik/a rticle/view/622/382

Sukamto, R. A., \& Salahuddin, M. (2014). Rekayasa Perangkat Lunak. Informatika. 